\title{
ERROR OF CONTROL OF ELECTRICAL INSULATION STRUCTURES BY DIELECTRIC ABSORPTION PARAMETERS ACCORDING TO THE CONCEPT OF UNCERTAINTY OF MEASUREMENTS
}

\begin{abstract}
Introduction. Measurements on alternating current of dielectric absorption parameters - capacitance and dielectric loss tangent tg $\delta$ allow us to evaluate the quality of insulation of cables, electrical machines, transformers, etc., both at the technological stage of manufacture and in operation. An increase in the reliability of the measurement result of the parameters is provided by a decrease in the measurement error due to the improvement of measuring instruments and measurement methods and an increase in the number of measurements Purpose. The estimation of the error of control of electrical insulation structures by dielectric absorption parameters in accordance with the concept of measurement uncertainty. Methodology. The error of measurements of the capacitance and the tangent of the dielectric loss angle is estimated using the example of a twisted unshielded pair of category 5e. A statistical analysis of the results of multiple measurements of the capacitance and the tangent of the dielectric loss angle of an unshielded cable is carried out. The linear regression equations for the measured values of the dielectric absorption parameters of the number of measurements are obtained. Practical value. Ensuring unity in the methods for estimating the error of measurement results, both when using the traditional concept of "measurement result error" and when introducing the concept of "measurement result uncertainty" into practice, it will allow to unambiguously interpret and correctly compare the results of measurements of the capacitance and tangent of the dielectric loss angle of electrical insulation structures. References 16, figures 3.

Key words: dielectric absorption parameters, capacitance, dielectric loss tangent, multiple measurements, measurement error, standard uncertainty, expanded uncertainty, twisted pair, digital immitance meter.
\end{abstract}

Представлено методологію оцінки похибки вимірювань параметрів діелектричної абсорбції електроізоляційних конструкцій в рамках концепцї невизначеності вимірювань. Наведено статистичний аналіз результатів багаторазових вимірювань ємності і тангенса кута діелектричних втрат скручений пари неекранованого кабелю категорії 5е. Отримано рівняння лінійної регресії для виміряних значень параметрів діелектричної абсорбції від числа вимірів. Виконано оцінювання похибки вимірювань ємності і тангенса кута діелектричних втрат неекранованого кабелю. Бібл. 16, рис. 3.

Ключові слова: параметри діелектричної абсорбції, смність, тангенс кута діелектричних втрат, багаторазові вимірювання, похибка вимірювань, похибка вимірювань, стандартна невизначеність, розширена невизначеність, скручена пара, цифровий вимірювач імітансу.

Представлена методология оценки погрешности измерений параметров диэлектрической абсорбции электроизоляционных конструкций в рамках концепции неопределенности измерений. Приведен статистический анализ результатов многократных измерений емкости и тангенса угла диэлектрических потерь витой пары неэкранированного кабеля категории 5е. Получены уравнения линейной регрессии для измеренных значений параметров диэлектрической абсорбции от числа измерений. Выполнено оценивание погрешности измерений емкости и тангенса угла диэлектрических потерь неэкранированного кабеля. Библ. 16, рис. 3.

Ключевые слова: параметры диэлектрической абсорбции, емкость, тангенс угла диэлектрических потерь, многократные измерения, погрешность измерений, погрешность измерений, стандартная неопределенность, расширенная неопределенность, витая пара, цифровой измеритель иммитанса.

Introduction. Measurements on alternating current of dielectric absorption parameters - the capacitance $C$ and dielectric loss tangent $\operatorname{tg} \delta$ allow us to evaluate the quality of insulation of cables, electrical machines, transformers, etc., both at the technological stage of manufacture and in operation [1-4].

When presenting the results of measuring the dielectric absorption parameters, a certain quantitative characteristic of the quality of the obtained measurement result should be presented for the possibility of: assessing its reliability; comparisons with the values specified in the technical documentation, standards; comparisons with results obtained by other authors.

The increase in the reliability of the measurement result of the parameters is provided by reduction of error of measurements due to the improvement of measuring instruments and measurement methods and by increasing the number of measurements themselves [5-9].
Problem definition. When conducting multiple measurements, the procedure for estimating measurement errors is defined in [10-12]. Processing the observation results includes the following procedures:

1. Exclusion of known systematic errors from the observation results.

2. Calculation of the arithmetic mean value of the observation results, taken as the measurement result.

3. Calculation of the standard deviation of the observation result.

4. Identification and exclusion of results containing misses.

5. Calculation of the standard deviation of the measurement results.

6. Testing the hypothesis that the measurement results belong to the normal distribution law (for the number of measurements $n<10$, the hypothesis is not tested). 
7. Calculation of the random component of the error of the measurement result, taking into account the Student coefficient, depending on the accepted confidence probability $P$ and the number of observation results $(P=0.95$ at technical measurements $)$.

8. Calculation of the non-excluded systematic error of the measurement result (the limits of the allowed basic and additional errors of measuring instruments, as well as methodological errors and errors caused by other sources) [10-12].

By its definition, the error of the measurement result represents the deviation of the measurement result from the true (actual) value of the measured quantity, which is unknown in practice when measuring [10-12].

The concept of measurement uncertainty does not use the concepts of the true and actual values of the measured quantity. The result is considered reality, since the value of the true measurement is unknown [11-13].

The concept of uncertainty is the only internationally recognized measure of error assessment. Measurement uncertainty is considered as incomplete knowledge of the value of the measured quantity. To quantify this incompleteness, a probability distribution of the possible values of the measured quantity is introduced. The parameter of this distribution, called uncertainty, quantitatively characterizes the error of the measurement result [13].

Uncertainty can be expressed as standard deviation (standard uncertainty) or interval (extended uncertainty) and calculated by method A (based on a number of experimental data) or by method B (based on additional information) [13].

Uncertainty is a quantitative measure of how reliable an assessment of the measured quantity is the result obtained. Uncertainty does not mean doubt about the result, but, on the contrary, uncertainty implies an increase in the degree of reliability of the result.

Assessment of the measurement result and its uncertainty is carried out in the following sequence: drawing up the measurement equation; assessment of input quantities and their standard deviations (uncertainties); assessment of the measured (output) value and its uncertainty; budgeting for uncertainty; assessment of the extended uncertainty of the measurement result; representation of the measurement result [13].

Extended uncertainty is interpreted as an interval containing a given fraction of the distribution of values that could reasonably be attributed to the measured quantity. Extended uncertainty in the concept of uncertainty does not play the role that is assigned in the concept of error. It is believed that the main result of the assessment is the total uncertainty $u_{C}$, and the expanded uncertainty differs from it by a constant coefficient, which is necessary in a number of special cases to show the reliability of the estimate. This coefficient can take values from 2 to 3 with a confidence level from 0.95 to 0.99 .

The goal of the paper is to evaluate the error of the control of electrical insulating structures according to the dielectric absorption parameters in accordance with the concept of measurement uncertainty.

Methodology for assessing the error of measuring capacitance and dielectric loss tangent. Inspections of electrical insulation structures in stationary laboratory conditions allow repeated observation of the measured dielectric absorption parameters. The results of repeated measurements of parameters even in stationary conditions differ from one another because the effect of many random interferences.

The standard ways to reduce the influence of random interferences is to calculate the average value and variance $s$ of the measured parameters [7-8, 14].

The main difference in the concepts (of uncertainty and of error) is in what value the variance (standard deviation) is attributed: to the actual value of the measured quantity or to the measurement result.

The initial data for estimating the standard measurement uncertainty are the results of multiple measurements $(N)$ of the capacitance $C_{i}$ and the dielectric loss tangent $\operatorname{tg} \delta_{i}$. Based on the results obtained, arithmetic means $\bar{C}_{i}, \overline{\operatorname{tg} \delta_{i}}$ are calculated which are an estimate of the capacitance and the dielectric loss tangent.

Here, for the electric capacitance, the average value

$$
\bar{C}_{i}=\frac{1}{N} \sum_{i=1}^{N} C_{i}
$$

The standard uncertainty associated with the estimate of $\bar{C}$ is the experimental standard deviation of the mean value and is equal to the positive square root of the experimental variance of the mean value.

Standard uncertainty of measurement $u\left(C_{i}\right)$ according to method $\mathrm{A}$

$$
u\left(C_{i}\right)=u_{A}\left(C_{i}\right)=\sqrt{\frac{1}{N(N-1)} \sum_{i=1}^{N}\left(C_{i}-\overline{C_{i}}\right)^{2}}
$$

for the measurement result of $C_{i}=\overline{C_{i}}$ calculated as the arithmetic mean.

In calculating the standard uncertainty in accordance with (2), $N$ independent random values of the form $C_{i}$ and one value $\bar{C}_{i}$ depending on them are used. Therefore, the number of degrees of freedom associated with (1) is $k=N-1$.

The sum of the squares in (2) refers to one degree of freedom, therefore, in the denominator of (2) there is the number $N-1$.

With an increase in the number of measurements, the arithmetic mean $\bar{C}_{i}$ tends to the true value of $\bar{C}_{i}$, provided that all systematic errors are eliminated. In this case, the difference between the error and $\left(C_{i}-\bar{C}_{i}\right)$ will tend to zero. Then the mathematical patterns of behavior of the aggregates of error and $u\left(C_{i}\right)$ will be similar.

When calculating the average, a series of random values of the capacitance $C_{i}$ (the tangent of the dielectric loss angle) are summed up as the results of individual observations. Each of the results $C_{i}$ can be represented as the sum of the mathematical expectation $\bar{C}$ and the random additive error $e$ distributed according to the normal law with zero mathematical expectation [14]

$$
C_{i}=\bar{C}+e .
$$

When summing $N$ random values of the form (3), the mathematical expectation of the term $\bar{C}$ increases by 
$N$ times, and of the random one (e) only by a factor of $\sqrt{N}$. In other words, $\bar{C}$ amplifies, and random $e$ decreases. As a result, the average is less prone to fluctuations than the result of a single observation of $C_{i}$. The variance of the mean $s_{C}^{2}$ is $N$ times smaller than the variance of a single observation $s^{2}[6,14]$

$$
s_{C}^{2}=\frac{s^{2}}{N} \text {. }
$$

The accumulation of the results of $N$ measurements and the calculation of the average lead to a decrease in the width of the confidence interval by almost a factor of $\sqrt{N}$

$$
\widetilde{C}-t(k, p) \frac{s}{\sqrt{N}} \leq \bar{C} \leq \widetilde{C}+t(k, p) \frac{s}{\sqrt{N}},
$$

where $t(k, p)$ is the Student criterion selected with a confidence probability of $P$ (usually $P=0.95$ ) for the number of degrees of freedom $k$.

For example, at $N=100$, the width of the uncertainty interval decreases by 10 times. When using, for example, a digital immitance meter E7-14, an additional significant figure appears, indicating a decrease in the error of the measurement result [5].

Statistical analysis of the results of multiple measurements of dielectric absorption parameters. Testing the methodology for assessing the error of measuring the capacitance and the tangent of the dielectric loss angle in the concept of the uncertainty of measurements of electrical insulating structures is performed using an example of twisted unshielded pair of category $5 \mathrm{e}[15,16]$. The cable length is $100 \mathrm{~m}$. The capacitance and the dielectric loss tangent are measured at frequency of $120 \mathrm{~Hz}$ for 1 hour using a RLC E7-22 digital immittance meter under constant ambient air conditions under laboratory conditions. In real time, with a resolution of $1 \mathrm{~s}$, the results of measurements using the standard RS232 electrical interface are recorded in computer memory using software. The error of the meter is $0.7 \%$.

Figure 1 shows a 3D diagram of the temporal series of the electric capacitance and the dielectric loss tangent of a twisted unshielded pair of category.

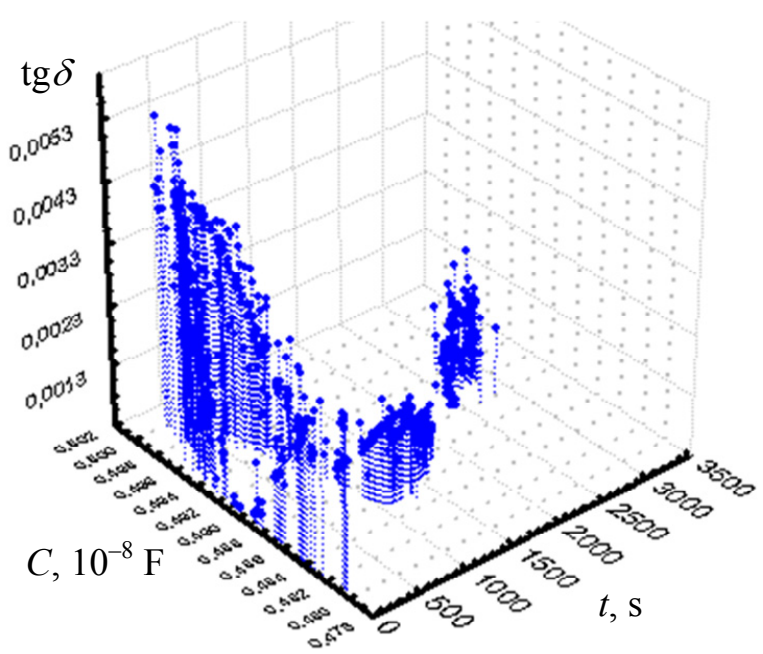

Fig. 1. Temporal series of dielectric absorption parameters of the twisted unshielded pair
The dynamics of the time variation of the capacitance (Fig. 2,a) and the dielectric loss tangent (Fig. 2,b) are almost identical. But the difference in time dependences and the wider spread of $\operatorname{tg} \delta$ values are due to the physical nature of the dielectric loss tangent. This parameter reflects not only polarization losses, but also electrical conductivity loses. The straight line in the Figures shows the regression line of the parameter values depending on the number of measurements $N$. The linear regression equations for the measured values of the dielectric absorption parameters on the number of measurements $N$ have the form

$$
\begin{gathered}
C=\left(0,4923-9,5794 \cdot 10^{-7} N\right) \cdot 10^{-8}, F \\
\operatorname{tg} \delta=0,0027-8,5081 \cdot 10^{-7} N .
\end{gathered}
$$

$$
C, 10^{-8} \mathrm{~F}
$$
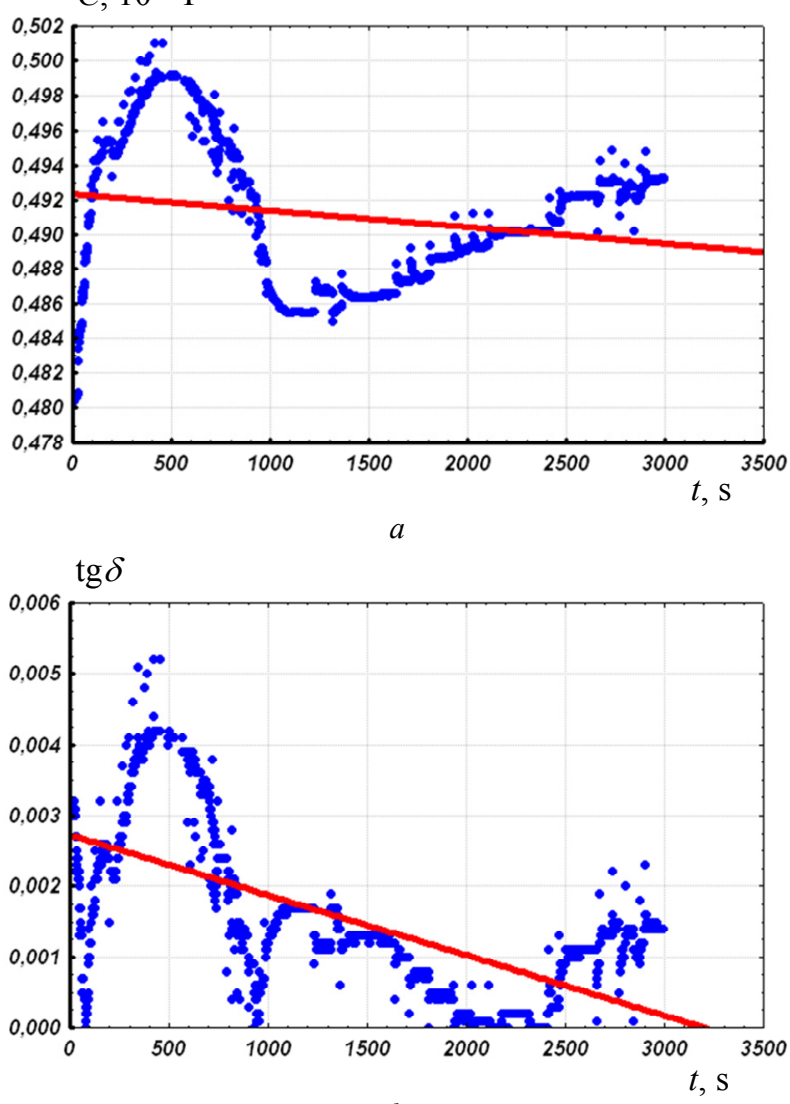

$b$

Fig. 2. Results of multiple measurements with a resolution of $1 \mathrm{~s}$ of the electrical capacitance and the tangent of the dielectric loss angle of a twisted pair

The average value of the capacitance is $0.4909 \cdot 10^{-8} \mathrm{~F}$; the standard deviation is $0.00406 \cdot 10^{-8} \mathrm{~F}$; the maximum value is $0.501 \cdot 10^{-8} \mathrm{~F}$; the minimum value is $0.4803 \cdot 10^{-8} \mathrm{~F}$ (Fig. 3,a). The average value of the dielectric loss tangent is 0.001433 ; the standard deviation is 0.001128 ; the maximum value is 0.052 ; the minimum value is 0 , which may be due to insufficient sensitivity of the digital meter (Fig. 3,b). 

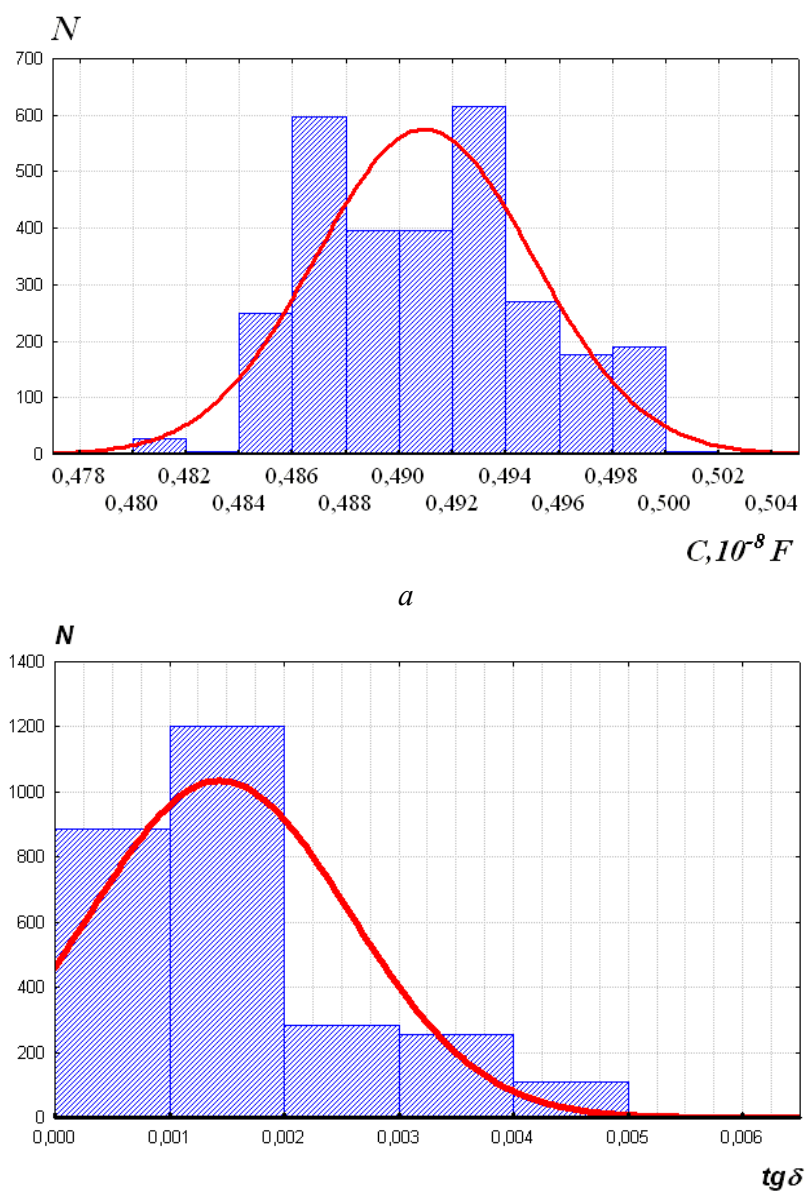

$b$

Fig. 3. Histogram of the observation results under the assumption of a normal distribution law of the measured dielectric absorption parameters

Assessment of error of measurements of capacitance and dielectric loss tangent. The calculated standard measurement uncertainty of type A, due to random sources of uncertainty having random nature, in accordance with (2) is $u\left(C_{i}\right)=7.5007 \cdot 10^{-13} \mathrm{~F}$ or $0.00153 \%$ for the capacitance; $u\left(\operatorname{tg} \delta_{i}\right)=2.0771 \cdot 10^{-5}$ or $1.45 \%$ for the dielectric loss tangent.

The standard measurement uncertainty of type B for systematic uncertainty sources, i.e. the instrument error is $1.9827 \cdot 10^{-11} \mathrm{~F}$ or $0.4 \%$ for the capacitance and $5.7983 \cdot 10^{-6}$ or $0.4 \%$ for the dielectric loss tangent, respectively.

The total standard uncertainty: $1.9841 \cdot 10^{-11} \mathrm{~F}$ or $0.4 \%$ for the capacitance and $2.1565 \cdot 10^{-11}$ or $1.5 \%$ for the dielectric loss tangent, respectively.

The expanded uncertainty of the measurement results with a digital immitance meter E7-22 is for a capacity $0.8 \%$; for the dielectric loss tangent $3 \%$, respectively, for the confidence probability (probability of coverage) $P=0.95$ and the coverage coefficient $k=2$.

\section{Conclusions.}

A methodology for assessing the error of measurements of dielectric absorption parameters of electrical insulation structures within the framework of the concept of measurement uncertainty is presented.

Testing the methodology for assessing the error of control of electrical insulating structures in terms of the capacitance and the dielectric loss tangent in the concept of measurement uncertainty is carried out on the example of a twisted unshielded pair of category $5 \mathrm{e}$.

A statistical analysis of the results of multiple measurements of the capacitance and the tangent of the dielectric loss angle of an unshielded cable is carried out. The linear regression equations for the measured values of the dielectric absorption parameters on the number of measurements are obtained.

The error of measuring the capacitance and the tangent of the dielectric loss angle of an unshielded cable has been evaluated. The standard measurement uncertainty of type A is $0.00153 \%$ for the capacitance and $1.45 \%$ for the dielectric loss tangent. The expanded uncertainty of the measurement results with an E7-22 digital immitance meter for the confidence probability (probability of coverage) $P=0.95$ and the coverage coefficient $k=2$ is $0.8 \%$ and $3 \%$ for the capacitance and the dielectric loss tangent, respectively.

Ensuring unity in the methods for assessing the error of measurement results, both when using the traditional concept of «measurement result error» and when introducing the concept of «measurement result uncertainty» into practice, will allow to unambiguously interpret and correctly compare the results of measurements of the capacitance and the tangent of the dielectric loss angle of electrical insulation structures.

\section{REFERENCES}

1. Liu T., Fothergill J., Dodd S., Nilsson U. Dielectric spectroscopy measurements on very low loss cross-linked polyethylene power cables. Journal of Physics: Conference Series, 2009, vol.183, p. 012002. doi: 10.1088/17426596/183/1/012002.

2. Setayeshmehr A., Fofana I., Eichler C., Akbari A., Borsi H., Gockenbach E. Dielectric spectroscopic measurements on transformer oil-paper insulation under controlled laboratory conditions. IEEE Transactions on Dielectrics and Electrical Insulation, 2008, vol.15, no.4, pp. 1100-1111. doi: 10.1109/tdei.2008.4591233.

3. Gavrilă Doina Elena. Dielectric Spectroscopy, a Modern Method for Microstructural Characterization of Materials. Journal of Materials Science and Engineering A, 2014, no.1, pp. 18-26. doi: 10.17265/2161-6213/2014.01.003.

4. Bezprozvannych G.V., Roginskiy A.V. Dielectric spectroscopy of casing thermosetting composite electrical insulation system of induction traction electric machines. Electrical engineering \& electromechanics, 2018, no.1, pp. 1720. doi: 10.20998/2074-272X.2018.1.02.

5. Bezprozvannych G.V., Naboka B.G. Influence of parasitic capacitance on the results of measurements of parameters of multicore cables in assessing their technical condition. Electricity, 2011, no.5, pp. 27-36. (Rus).

6. Bezprozvannych G.V., Boyko A.M. Electrostatic processes in power cables. Electrical engineering \& electromechanics, 2013, no.4, pp. 27-31. (Ukr).

7. Hart H. Vvedenie v izmeritel'nuiu tekhniku [Introduction to Measurement Technology]. Moscow, Mir Publ., 1999. 391 p. (Rus).

8. Markov N.S. Osnovy teorii obrabotki rezul'tatov izmerenii [Fundamentals of the theory of processing measurement results]. Moscow, Standards Publishing House, 1991. 176 p. (Rus).

9. DSTU 4743: 2007. Provody samoutrymni izolovani ta zakhyshcheni dlia povitrianykh linii elektroperedavannia. Zahalni tekhnichni umovy [State Standard of Ukraine DSTU 
4743: 2007. Wires self-supporting insulated and protected for overhead transmission lines. General specifications]. Kyiv, 2007. 26 p. (Ukr).

10. DSTU ISO 10012:2005 Systemy keruvannia vymiriuvanniam. Vymohy do protsesiv vymiriuvannia ta vymiriuvalnoho obladnannia [State Standard of Ukraine DSTU ISO 10012. Measurement management systems requirements for measurement processes and measuring equipment]. (Ukr).

11. Mironov E.G., Firsanov V.A. Errors and measurement uncertainties. Instrumentation Practice, 2004, no.2, pp. 79-84. (Rus).

12. Kuznetsov V.P. Error of Measurement and Uncertainty: A Comparison. Measurement Techniques, 2003, vol.46, iss.8, pp. 751-760. doi: 10.1023/a:1026157229045.

13. JCGM 100:2008. Evaluation of measurement data. Guide to the expression of uncertainty in measurement. Available at: http://www.bipm.org/ utils/common/documents/jcgm (accessed 17 June 2018).

14. Goltsman F.M. Fizicheskii eksperiment $i$ statisticheskie vyvody [Physical experiment and statistical conclusions]. Leningrad, Leningrad University Publ., 1982. 192 p. (Rus).
15. Boyko A.N. Drift in time capacity and dielectric loss tangent of unshielded and shielded network cables. Bulletin of NTU «KhPI», 2013, no.42, pp. 65-68. (Rus).

16. Bezprozvannych G.V., Boyko A.M. Experimental determination of triboelectric potential in unshielded and shielded network cables. Electrical engineering \& electromechanics, 2012, no.3, pp. 56-60 (Ukr).

Received 12.11.2019

G.V. Bezprozvannych ${ }^{1}$, Doctor of Technical Science, Professor,

I.A. Kostiukov ${ }^{1}$, Candidate of Technical Science,

${ }^{1}$ National Technical University «Kharkiv Polytechnic Institute», 2, Kyrpychova Str., Kharkiv, 61002, Ukraine, phone +380 577076010 ,

e-mail: bezprozvannych@kpi.kharkov.ua, iakostiukow@gmail.com

How to cite this article:

Bezprozvannych G.V., Kostiukov I.A. Error of control of electrical insulation structures by dielectric absorption parameters according to the concept of uncertainty of measurements. Electrical engineering \& electromechanics, 2020, no.1, pp. 47-51. doi: 10.20998/2074-272X.2020.1.07. 